\title{
RICE CROP MONITORING USING SENTINEL-1 C-BAND DATA
}

\author{
C. Dineshkumar ${ }^{1, *}$, J. Satishkumar ${ }^{2}$ \\ ${ }^{1}$ Student, Remote Sensing and GIS, SRM Institute of Science and Technology, Chennai - \\ *dineshchandrasekar.dk@gmail.com \\ ${ }^{2}$ Department of Civil Engineering, SRM Institute of Science and Technology, Chennai.
}

Commission III, WG III/10

KEY WORDS: rice, sentinel-1, phenology, rice monitoring, back scattering.

\begin{abstract}
:
Among the cereal grains, rice is staple food for $1 / 2$ of the world population. In Asian countries as population increases, the demand for rice also increases. For this future demand rice, biophysical variables are monitored for agricultural management and yield prediction using space borne satellite platform. While in satellite remote sensing there are numerous trouble in mapping and monitoring rice field, particularly in multi season paddy in rainy season, incorporating the changes in crop phenology, the impact of climate and farmland variability. To determine these issues Sentinel-1 was launched and provide opportunity to monitor rice crop, in $10 \mathrm{~m}$ spatial resolution, C-band, dual polarization image with 12 days revisit. A rice field in Kulithalai, Tamilnadu is utilized as examination. In this study Sentinel-1 data, which can recognize little vegetation difference at firmly found ground truth (GT) point. While observing the different growing stages of rice, the volume scattering segment proportion was increased though the surface scattering segment proportion for the most part diminished. During rice growing stages, surface scattering component ratio decreased, while volume scattering ratio will be increased. This study describes how multi temporal observation by SAR has extent capacity for estimating rice growing land and monitoring growing stages and also interpret $\sigma^{0} \mathrm{VV}$ and $\sigma^{0} \mathrm{VH}$ back scattering co-efficient. These are examined by knowing crop parameters like leaf area index, plant height, no. of panicle $/ \mathrm{m} 2$ and no. of grains $/ \mathrm{m}^{2}$.
\end{abstract}

\section{INTRODUCTION}

Rice (O.sativa) is stable food for the $1 / 2$ part of the world's total population. It also one of the world's major food crops, involves in excess of $11 \%$ of world's aggregate developed land. Over $90 \%$ of the world's rice production and used in Asian continents. About $80 \%$ of world's rice is cultivated by smallscale agriculturists with low-income and they are in developing countries and its age uses 140 million rice-developing families (FAO, 2014). It is monocot and conventionally practiced as a yearly plant, notwithstanding the way that in tropical regions it can get by as a persevering and can convey a ratoon crop for up to 30 years. Biophysical parameters such as biomass, yield estimation, leaf are index (LAI), and water holding level, are critical for farmers in rice development. For instance, dry biomass will provide yield. Rice advancement is suitable to countries and areas with low work costs and high precipitation, as it is work genuine to create and requires sufficient water. In any case, rice can be produced in every way that really matters wherever, even on a slope or mountain zone with the usage of water-controlling yard systems. Convenient and exact estimation of the territory and conveyance of paddy rice crops is valuable data for governments, organizers, and chiefs who plan approaches as far as food security and environmental maintainability. Regular information of rice growing region, season and yield are sub-national data, which are a fundamental piece of numerous nation's accounting process however current framework may not be adequate to take care of the data need with regards to food security and policy [2]. Rice farming is associated with different natural viewpoints, from water to environmental change because of the high discharges of methane. Hence, a more drawn out term between yearly observing is likewise required so as to contemplate the effect of the adjustments in rice zones and in social practices that are probably going to happen in the following a long time to confront the monetary and ecological studies. The utilization of optical data for Crop timely monitor and its management has been carried out in large number of studies in the last two decades. Be that there is a limited restriction of Earth Observation (EO) frameworks carrying optical sensors that cannot penetrate into cloud conditions throughout crop growing stages. For this concern, Synthetic Aperture Radar (SAR) plays a vital role in cloud infiltration and provides data for both day and night because of their own emitting source and acquisition [1]. With the accessibility of Sentinel-1 data having a high spatial resolution of $(10 \mathrm{~m} \times 10 \mathrm{~m})$ and revisit (each 6 days), it has a huge number of utilizations even at the land level. Sentinels-1A and-1B (all in all called as Sentinel-1) are remote sensing satellites as of late propelled and kept up by European Space Agency (ESA). It has a SAR C-band with frequency of $5.405 \mathrm{GHz}$ (ESA, 2013). This band of radar is especially important for observing lowland rice condition because of its affectability to water and product geometry. With the two satellites now circling 180o separated, Sentinel-1 can give allclimate, day and night, worldwide perception each six (6) days (ESA, 2013). All the more in this way, its information is downloadable on free of cost, full and open information arrangement embraced by the Copernicus program for all Sentinel information (ESA, 2013). Just a straightforward client enrollment is required to get data. Different studies carried over on rice-grown area by utilizing C-band SAR have just been directed. Notwithstanding, none difficult to apply it in the small scale imagining that at a single pixel level. The vast majority of these studies concentrated on the distinguishing information and mapping of rice zones for arrangement and arranging purpose. Different investigations investigated the displaying of rice parameters 


\section{STUDY AREA}

It is located at $78.29^{\circ} \mathrm{E} 10.56^{\circ} \mathrm{N}$. It is arranged on the banks of Cauvery River. This area comes under Cauvery delta zone. The geography is plain. Alluvial \& red soil types are present in Cauvery delta. The temperature ranges from most extraordinary of $32.7^{\circ} \mathrm{C}$ to no less than $24{ }^{\circ} \mathrm{C}$. Like whatever is left of the state, April - June are the most sizzling months and December January are the cold season. It gets an ordinary of $27 \mathrm{~cm}$ yearly or, as such the state typical of $1,008 \mathrm{~mm}$. The South-west rainstorm, start in June and persevering to August, receive lacking precipitation. Heave of the precipitation is gotten in the midst of the North-East rainstorm in the extended lengths of October-December. Ordinary number of stormy days range from 35-40 reliably. The principal crops of the kulithalai are paddy, millets, pulses, oilseeds, sugarcane and banana.

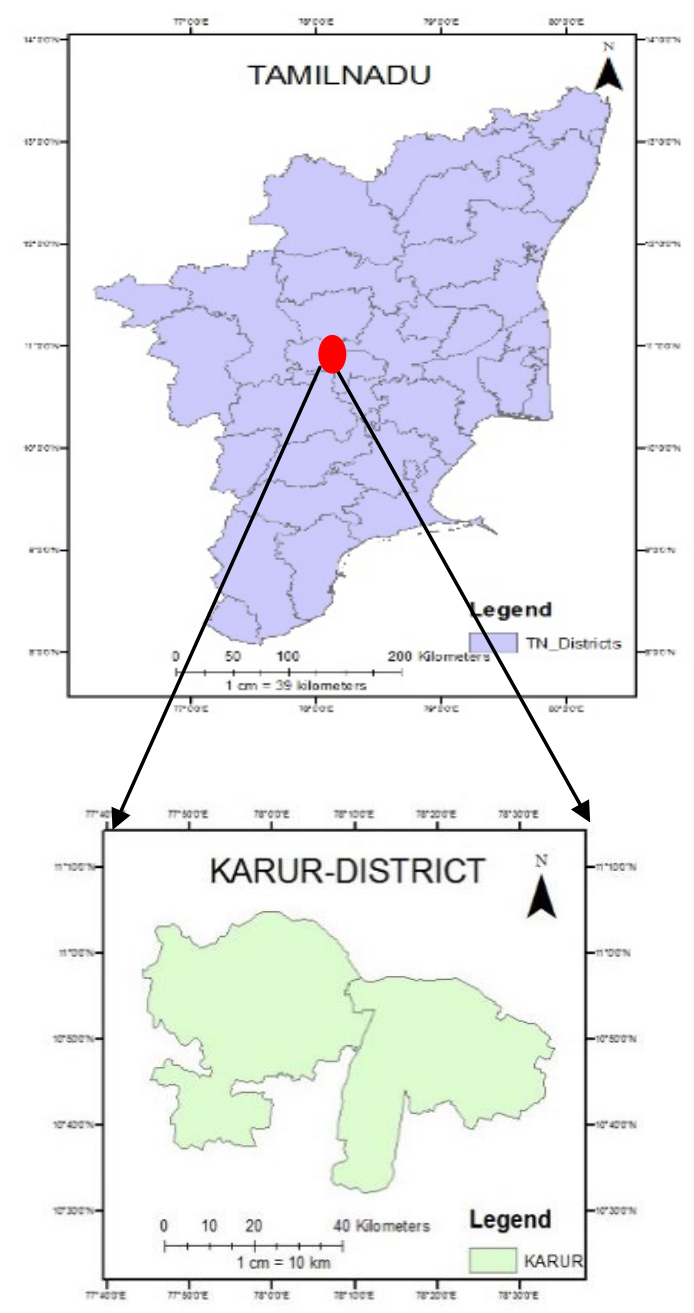

Figure 1. Study Area

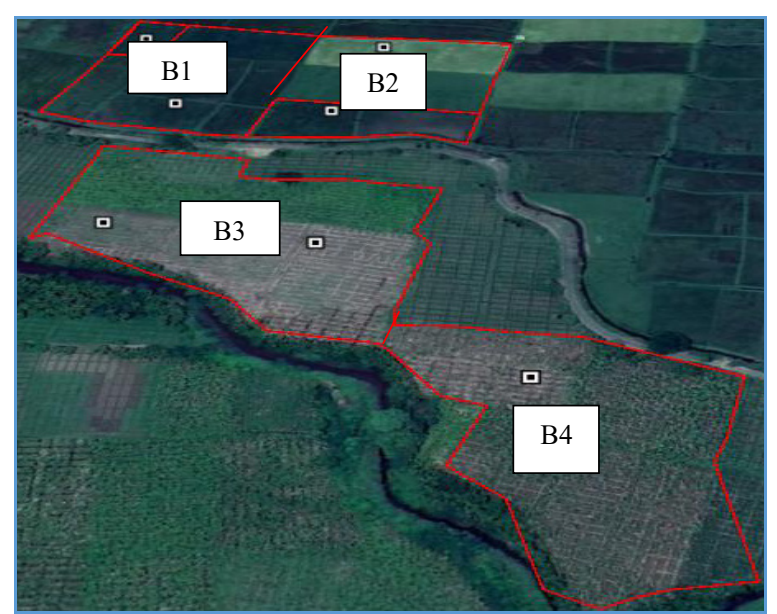

https://earth.google.com/web/@10.92821122,78. $\underline{41468533,87.16079092 \mathrm{a}}$

Figure 2. Rice growing blocks $(1,2,3,4)$

\section{MATERIALS AND METHOD}

Sentinel-1A SAR image was downloaded from Copernicus Satellite data hub where all SAR images can be easily downloaded free of cost. Radiometric calibration is been done to represent the original pixel value of radar backscatter from reflected surface.

\begin{tabular}{|l|l|c|l|}
\hline Name & Resolution & \multicolumn{1}{|c|}{$\boldsymbol{\Lambda}$} & \multicolumn{1}{|c|}{ Description } \\
\hline VV & $10 \mathrm{~m}$ & $5.405 \mathrm{GHz}$ & $\begin{array}{l}\text { Single co-polarization, } \\
\text { vertical } \\
\text { transmit/vertical } \\
\text { receive }\end{array}$ \\
\hline $\mathrm{VH}$ & $10 \mathrm{~m}$ & $5.405 \mathrm{GHz}$ & $\begin{array}{l}\text { Dual-bandcross- } \\
\text { polarization, vertical } \\
\text { transmit/horizontal } \\
\text { receive }\end{array}$ \\
\hline
\end{tabular}

Table 1. Sentinel-1 Description

It necessary for quantitative use of SAR data. Correction are done based on product's metadata. Speckle filter helps to reduce the speckle that will reduce the resolution of the image or produce blurred image. It is occurred due to irregular constructive and damaging interference brings salt and pepper noise in image. While in speckle filter, there are many filter options. They are Intensity driven adaptive neighborhood (IDAN) Lee BOXAR, Frost, Gamma MAP, Lee- Sigma, Median, Refined Lee. In these Lee, Lee-sigma and Frost are mainly for de-speckling [17-20]. All filters will provide accuracy of $85.8 \%-87.7 \%$. The choice of filter is based upon amount of spatial averaging, degree of edge retention to be done and speckle statistics. Refined Lee filter is used here to done speckle filter. Terrain correction has done to geocode the SAR data by correcting SAR geometric distortions using a DEM and produce projected map. Geocoding is done to convert SAR image from SLC or GRD Geometry into coordinate system. Terrain Geocoding utilizes Digital Elevation Model (DEM) to rectify inherent SAR geometry impact such as layover, foreshortening and shadow. For interferometric processing, SAR images should be co-registered into stack. One picture is kept as reference and other images are arrange according to reference image. 


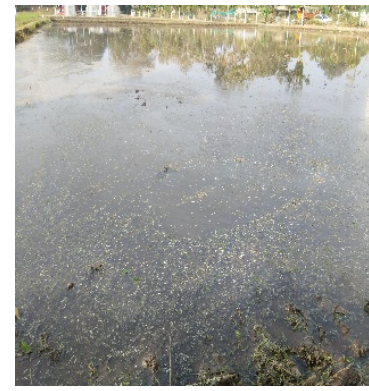

1.Ploughed land

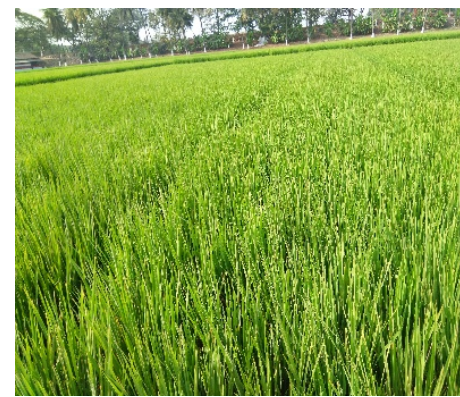

5.Heading

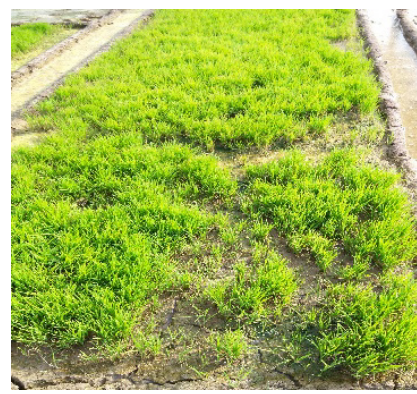

2.Nursery

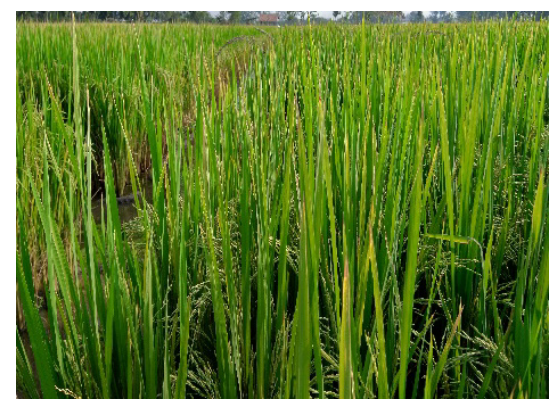

6.Flowering

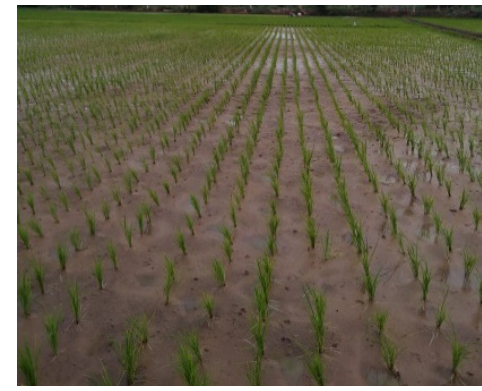

3.Transplanting

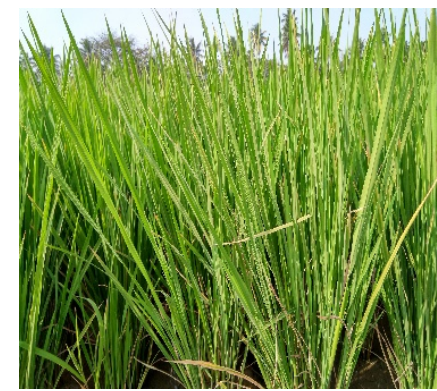

4.Tillering

Table 2. Photographs taken at different growth stages of rice fields

Other image pixels are moved to align with reference image for sub-pixel accuracy. Co-registration guarantees that each ground target adds to equivalent pixel as reference image.

\begin{tabular}{|c|c|c|c|c|}
\hline $\begin{array}{c}\text { Acquisition } \\
\text { Date }\end{array}$ & Mode & Pass & $\begin{array}{c}\text { Product } \\
\text { Type }\end{array}$ & $\begin{array}{c}\text { Swath } \\
\text { width }\end{array}$ \\
\hline $09-09-2018$ & IW & Ascending & GRD & $250 \mathrm{~m}$ \\
\hline $21-09-2018$ & IW & Ascending & GRD & $250 \mathrm{~m}$ \\
\hline $03-10-2018$ & IW & Ascending & GRD & $250 \mathrm{~m}$ \\
\hline $27-10-2018$ & IW & Ascending & GRD & $250 \mathrm{~m}$ \\
\hline $08-11-2018$ & IW & Ascending & GRD & $250 \mathrm{~m}$ \\
\hline $20-11-2018$ & IW & Ascending & GRD & $250 \mathrm{~m}$ \\
\hline $02-12-2018$ & IW & Ascending & GRD & $250 \mathrm{~m}$ \\
\hline $14-12-2018$ & IW & Ascending & GRD & $250 \mathrm{~m}$ \\
\hline $26-12-2018$ & IW & Ascending & GRD & $250 \mathrm{~m}$ \\
\hline
\end{tabular}

*IW-Interferometric Wide Swath ;*GRD-Ground Range Detected

Table 3. Satellite Acquisition Details

\section{RICE GROWTH STAGES AND PRACTICES}

The phenological stages of rice are leaf development, tillering, stem elongation, heading, grain development and ripening. The rice growing area was shown in Figure 1 and field is shown in Figure 2. There are two rice varieties was grown in study area i.e. CR 1009 and White Ponni. CR1009 was grown in Block 1 and 2. White Ponni was grown in Block 3 and 4. CR 1009 was long duration varieties grown up to 155-160 days and provide average yield of $5700 \mathrm{~kg}$ per hectare. While White ponni is medium duration, varieties grown up to 135-140 days and provide average yield of $4500 \mathrm{~kg}$ per hectare. In this study area nursery was grown in block 1 from there transplanted to all blocks. Before ploughing 10 to 12tones per hectare of FYM was applied. Rice production is practiced in SRI (System of Rice Intensification). Within 8-12 days Seedlings are transplanted to main filed at 2-3 leaf grown stage because for potential tillering and rooting ability. It tends to provide maximum yield potential. Normally clump of seedling was sown in field but in SRI Single seedling was sown. By making mark using rope spacing was maintained correctly. $25 \times 25 \mathrm{~cm}$ spacing was practiced while transplanting for both plant-to-plant and row-to-row spacing about 16 plants $/ \mathrm{m}^{2}$. Plough of in-situ grown 45 to 60 days green manure crops. However, no chemical fertilizer is required, so the field is completely organic. The water level of field is 2 to $3 \mathrm{~cm}$. From panicle initiation to maturity stage one inch of water is stagnated. After grains in the panicle, gets hardened 70 percent of water drained from the field. The crop become fully yellowish once they attain maturation stage. At harvesting stage, crops are cut using sickle and thrashed for removing grains from panicle.

\section{RESULT AND DISCUSSION}

At initial stage field contains only soil, so there will be more backscatter. Block 1 is used as nursery for all the four blocks. Therefore, there will be less backscatter compared to other blocks. Yellow color lines and Red color lines in Figure 3 and Figure 4 represent early transplanted and late transplanted rice crop. In initial rice growth stages shows average VH backscatter value of $-20 \mathrm{db}$ and VV backscatter value is $-12 \mathrm{db}$. VV and VH backscatter value after harvesting stage is $-12 \mathrm{db}$ and $-17 \mathrm{db}$. In grain, filling stage there will be peak in both $\mathrm{VV}$ and $\mathrm{VH}$ polarization. In the study Site VV, polarization provides good result in comparison with $\mathrm{VH}$ polarization. 


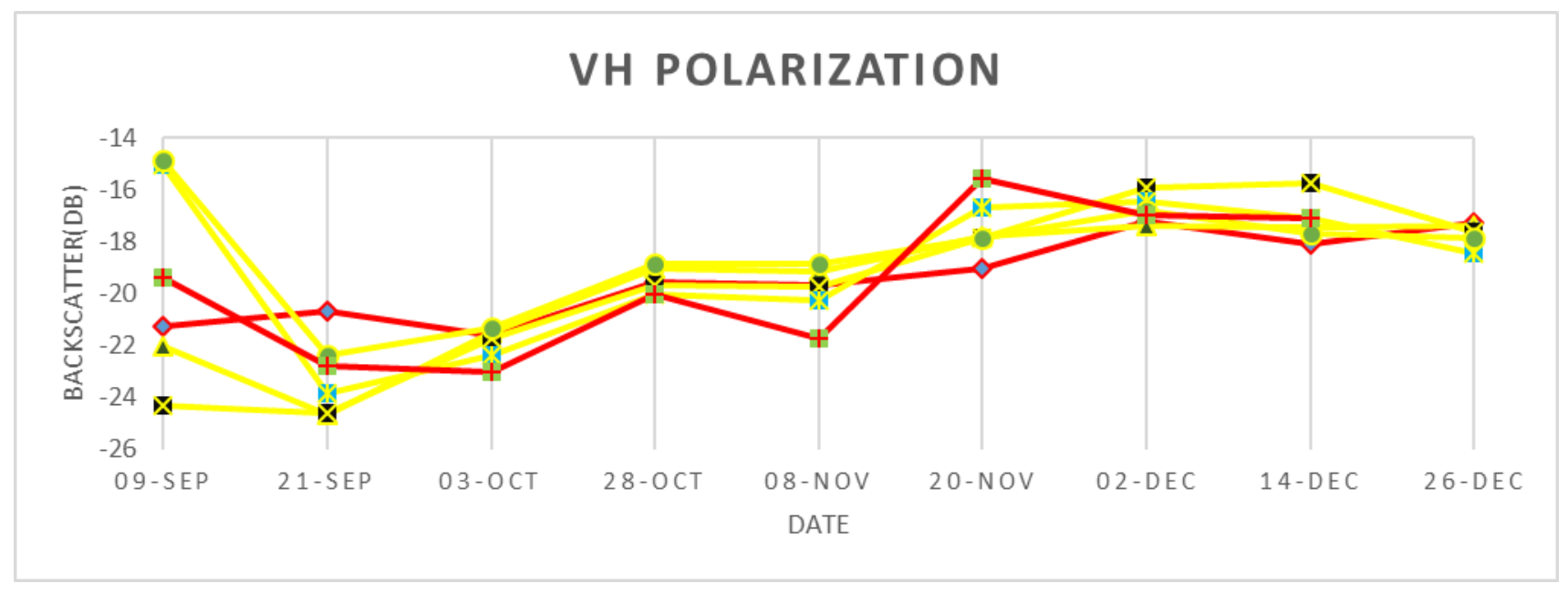

Figure 3. Backscatter (db) values for VH Polarization of Rice blocks

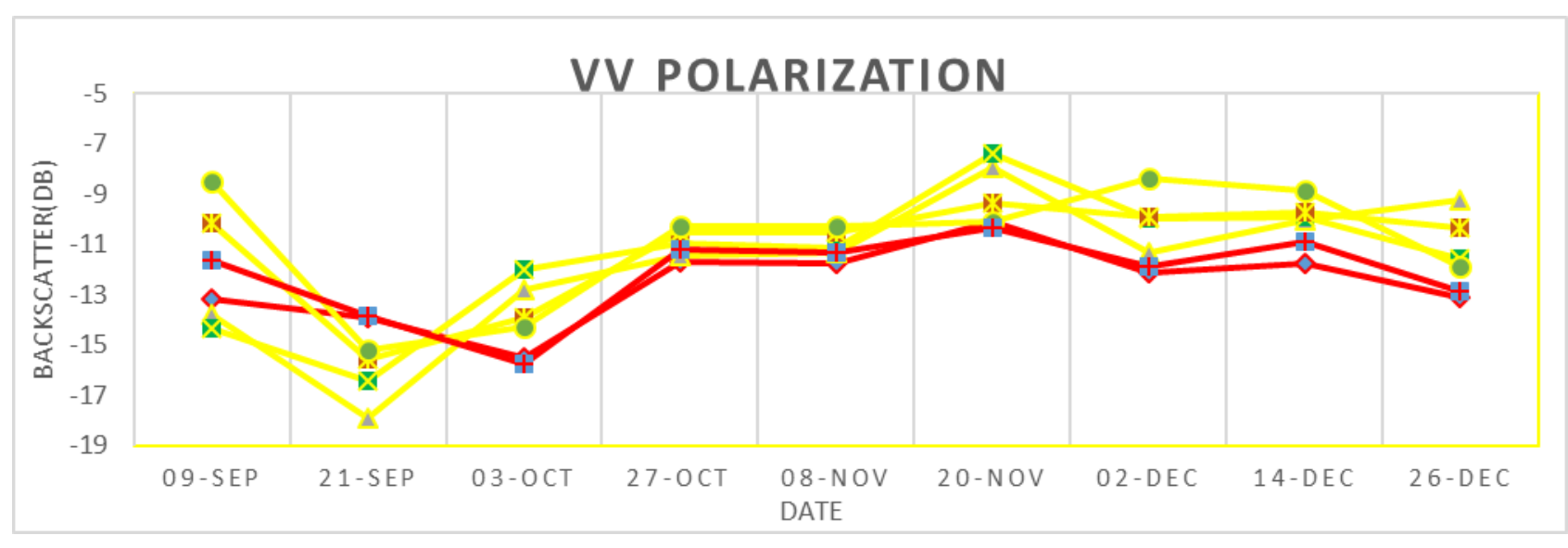

Late Transplanted

Transplanted

Early

Figure 4. Backscatter $(\mathrm{db})$

Rice blocks

values for VV Polarization of

\section{REFERENCES}

Blaes, X., Vanhalle L. and Defourny P., 2005, Efficiency of Crop identification based on optical and SAR image time series, Remote Sensing of Environment, vol. 96, n. 3-4, pp. 352-365.

European Space Agency. (2013). Sentinel-1 user handbook [ESA Standard Document]. European Commission, European Union.

Gumma M K, Thenkabail P S, Maunahan A, Islam S, Nelson A 2014 Mapping seasonal rice cropland extent and area in the high cropping intensity environment of Bangladesh using MODIS $500 \mathrm{~m}$ data for the year 2010. ISPRS J. Photogram my. Remote Sens. 91, pp. 98-113.

G. Vasile, E. Trouvé, J. S. Lee, and V. Buzuloiu "Intensitydriven adaptive-neighborhood technique for polarimetric and interferometric SAR.
https://earth.esa.int/documents/653194/656796/Speckle Filterin g.pdf

Inoue, Y., Sakaiya, E. and Wang, C., 2014, Capability of Cband backscattering coefficients from high-resolution satellite SAR sensors to assess biophysical variables in paddy rice, Remote Sensing of Environment, vol. 140, pp. 257-266.

Moran, M. S.et al., 1997, Combining multi-frequency microwave and optical data for crop management, Remote Sensing of Environment, vol. 61, n.1, pp. 96-109.

P. Kupidura, "Comparison of Filters Dedicated to Speckle Suppression in SAR Images," ISPRS-International Archives of the Photogrammetry, Remote Sensing and Spatial Information Sciences, pp. 269-276, 2016.

Xiao, X, Boles S, Frolking S, Li C, Babu J Y, Salas W, Moore B 2006 mapping paddy rice agriculture in South and Southeast Asia using multi-temporal MODIS images Remote Sens. Environ. 100, pp.95-113 
Ulaby, F., Allen, C., Eger, G., Kanemasu, E. Relating the microwave-backscattering coefficient to leaf area Index. Remote Sens. Environ. 1984, 14, pp. 113-133. 